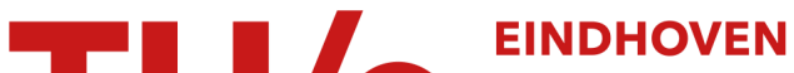 UNIVERSITY OF TECHNOLOGY
}

\section{Interfacial dynamics in diffusion-driven phase transformations}

\section{Citation for published version (APA):}

Pieraggi, B., Rapp, R. A., Loo, van, F. J. J., \& Hirth, J. P. (1990). Interfacial dynamics in diffusion-driven phase transformations. Acta Metallurgica et Materialia, 38(9), 1781-1788. https://doi.org/10.1016/0956-7151(90)90020$\mathrm{H}$

DOI:

10.1016/0956-7151(90)90020-H

Document status and date:

Published: 01/01/1990

\section{Document Version:}

Publisher's PDF, also known as Version of Record (includes final page, issue and volume numbers)

\section{Please check the document version of this publication:}

- A submitted manuscript is the version of the article upon submission and before peer-review. There can be important differences between the submitted version and the official published version of record. People interested in the research are advised to contact the author for the final version of the publication, or visit the $\mathrm{DOI}$ to the publisher's website.

- The final author version and the galley proof are versions of the publication after peer review.

- The final published version features the final layout of the paper including the volume, issue and page numbers.

Link to publication

\section{General rights}

Copyright and moral rights for the publications made accessible in the public portal are retained by the authors and/or other copyright owners and it is a condition of accessing publications that users recognise and abide by the legal requirements associated with these rights.

- Users may download and print one copy of any publication from the public portal for the purpose of private study or research.

- You may not further distribute the material or use it for any profit-making activity or commercial gain

- You may freely distribute the URL identifying the publication in the public portal.

If the publication is distributed under the terms of Article $25 f a$ of the Dutch Copyright Act, indicated by the "Taverne" license above, please follow below link for the End User Agreement:

www.tue.nl/taverne

Take down policy

If you believe that this document breaches copyright please contact us at:

openaccess@tue.nl

providing details and we will investigate your claim. 


\title{
INTERFACIAL DYNAMICS IN DIFFUSION-DRIVEN PHASE TRANSFORMATIONS
}

\section{B. PIERAGGI ${ }^{1}$, R. A. RAPP ${ }^{2}$, F. J. J. van LOO $^{3}$ and J. P. HIRTH ${ }^{4}$}

'Laboratoire Métallurgique Physique, UA-445 CNRS, ENSC Toulouse, F-31077, Toulouse, France ${ }^{2}$ Department Materials Science and Engineering, Ohio State University, Columbus, OH 43210, U.S.A. ${ }^{3}$ Laboratory of Physical Chemistry, Eindhoven University Technology, Eindhoven, The Netherlands ${ }^{4}$ Department of Mechanical \& Materials Engineering, Washington State University, Pullman, WA 99164, U.S.A.

(Received 28 June 1989; in revised form 7 February 1990)

\begin{abstract}
The migration of ledges in a semicoherent $\alpha / \beta$ interface is considered to participate in solid-state transformations driven by diffusion. The advance of the ledge and/or the progress of the transformation can require the climb of misfit dislocations both in the ledge and in its path. The creation or annihilation of vacancies required for the transformation and the ledge advance is provided by a combination of three vacancy sources or sinks: (a) the net vacancy flux to/from the interface resulting from the difference in lattice plane shift (Kirkendall effect) within the two contacting phases, (b) the climb of misfit dislocations from the interface into the bulk of the $\alpha$ and $\beta$ phases, and (c) the climb of misorientation dislocations within the interface. Thus, the dynamic action of the interface during the phase transformation would include: (i) climb of misfit dislocations out of the interface, with ensuing dissociation into glissile dislocations which resupply the interface by return glide, and (ii) climb of misorientation dislocations in the interface necessitating a continuing arrival of such dislocations from sources in the bulk or in the interface.
\end{abstract}

Résumé-La migration d'une marche d'un interface $\alpha / \beta$ semicohérent intervient dans les transformations solide-solide controlées par la diffusion. Le déplacement d'une marche et/ou le déplacement de l'interface nécessite la montée des dislocations interfaciales. Dans l'hypothèse de la conservation du nombre total de noeuds de réseaux, la création ou l'annihilation des lacunes nécessaires à la transformation et au déplacement des marches est la résultante de trois sources ou puits de lacunes d'origine différente: (a) la création ou l'annihilation de lacunes par l'interface compensant la différence de déplacement des plans atomiques (Effet Kirkendall) au sein des deux phases, (b) la montee des dislocations de vernier de l'interface vers les phases $\alpha$ et $\beta$, et (c) la montée des dislocations de désorientation dans l'interface. De ce fait, le rôle de l'interface au cours d'une transformation de phase doit tenir compte: (i) de la montée des dislocations de verniers hors de l'interface, la dissociation de ces dislocations, généralement sessiles, en dislocations glissiles permettant leur retour vers l'interface par glissement, et (ii) de la montée des dislocations de désorientation dans le plan de l'interface, ce qui nécessite la présence d'une source permettant le renouvellement continu de ces dislocations.

Zusammenfassung-Die Wanderung von Stufen über eine semikohärente $\alpha / \beta$-Grenzfläche wird als ein Teil der diffusionsgesteuerten Festkörperumwandlung angesehen. Die Bewegung der Stufe und/oder das Fortschreiten der Umwandlung kann dazu führen, daß Fehlpassungsversetzungen in der Stufe und in deren Pfad klettern müssen. Die für Umwandlung und Stufenbewegung benötigte Bildung oder Vernichtung der Leerstellen läuft über eine Kombination von drei Leerstellenquellen oder -senken: (a) der Nettoleerstellenfluß von/zu der Grenzfläche, herrührend aus dem Unterschied in der Verschiebung der Gitterebenen (Kirkendall-Effekt) innerhalb der zwei sich berührenden Phasen, (b) das Klettern der Fehlpassungsversetzungen aus der Grenzfläche in das Volumen der $\alpha$ - und $\beta$-Phase und (c) das Klettern von Fehlorientierungsversetzungen innerhalb der Grenzfläche. Daher umfaßt die dynamische Wirkung der Grenzfläche während der Phasenumwandlung: (i) Klettern von Fehlpassungsversetzung aus der Grenzfläche mit nachfolgender Dissoziation in Gleitversetzungen, welche wiederum die Grenzfläche durch Rückgleiten versorgen und (ii) Klettern von Fehlorientierungsversetzungen in der Grenzfiäche, welches eine kontinuierliche Versorgung mit solchen Versetzungen aus Quellen im Volumen oder in der Grenzfläche erfordert.

\section{INTRODUCTION}

The role of dislocation climb in the creation and annihilation of vacancies for interdiffusion in an isomorphous system $(\mathrm{Cu}-\mathrm{Ni}, \mathrm{Ag}-\mathrm{Au}$, etc.) is rather well understood [1-3]. Matthews [4, 5] and Beers and
Mittemeijer [6] have shown that during diffusion the misfit dislocations originally present at a $\mathrm{Cu}-\mathrm{Ni}$ interface are distributed into the diffusion zone, where they account for a continuous variation in the lattice parameter with changing composition. By this mechanism, the original misfit interfacial dislocations 
are redistributed and, to first order, conserved as the original interface loses its identity, although subsequently they may be annihilated by recovery processes. The climb in the bulk of such dislocations originating from the interface would also account for the creation and annihilation of vacancies in the diffusion couple, which is required to compensate for differing intrinsic diffusion coefficients of the components and the resulting Kirkendall effect.

The exact behavior of an interphase interface during boundary migration associated with a solid-state phase transformation is a subject of great current interest. As considered in the preceding paper [7], for the diffusion-limited transformation between two binary disordered, substitutional solid solutions $(\alpha / \beta)$, any interphase interface must be able either to create or annihilate vacancies, depending upon the intrinsic diffusion coefficients for each component (A and B) in each phase, and upon the initial and interfacial concentrations of A and B in the diffusion couple. In the preceding paper, no structural mechanism was offered to achieve the creation or annihilation of vacancies in the interface, or to relate this process to the migration of the interphase interface which constitutes the phase transformation.

Because of a difference in lattice parameters and/or lattice structure, and/or a departure from a near-coincidence orientation, and $\alpha / \beta$ interphase interface in local stress-free equilibrium can be described by a more or less complex and dense array of intrinsic (misfit and misorientation) interface dislocations [8-13]. In addition, extrinsic interface dislocations can be present in the boundary. The extrinsic dislocations may have perfect lattice Burgers vectors of one or the other lattice or may dissociate into interface dislocations with smaller vectors belonging to the DSC lattice $[8,11]$ of the pair of phases meeting at the boundary. Intrinsic dislocations will have Burgers vectors related to the DSC lattice [11-13]. Ledges in the interface can also have both intrinsic and extrinsic dislocation character containing components both parallel and perpendicular to the adjacent terraces. Incoherent interfaces or those with very small 0-lattice unit cells can be also described formally by dislocation theory but the description is generally agreed to have little physical significance. On the other hand, many semicoherent or epitaxial interfaces or near-coincidence boundaries contain discrete sets of interface dislocations discernable by transmission electron microscopy [14]. Indeed, many interfaces once thought to be incoherent and structureless have been found to contain interface dislocation ledge character: these include the risers of macroscopic ledges in phase transformations and some massive transformation interfaces, for example [15].

We address two cases of dislocation/ledge activity in the present work. One is exemplified by the interface between two layers $\alpha$ and $\beta$, both growing (or shrinking) by diffusional processes with appreciable fluxes in both phases, illustrated in Fig. 2(a-c) in the preceding paper [7]. This example includes the case where one (or both) of the phases is an oxide. In this case, the macroscopic interface appears smooth, but microscopically can be described in terms of dislocations and ledges at the atomic level. The second case is represented by the diffusional growth of a precipitate with nominally planar habit planes, whereby the fluxes are largely confined to the matrix, the case in Fig. 2(d) in Ref. [7]. For this case, electron microscope observations indicate the presence of misfit dislocations, monatomic (structural) ledges and macroscopic growth ledges separating low-index terraces on the nominally planar habit planes [15].

The preceding paper points out that any migrating $\alpha / \beta$ interface participating in diffusional growth must be active in creating and/or annihilating vacancies. A recent paper by Pieraggi and Rapp [16] has proposed a model for vacancy annihilation for the growth of an $\mathrm{NiO}$ scale on $\mathrm{Ni}$ by the climb of a fraction of the misfit dislocations into the metal phase, with an associated redistribution (change in spacing) of the misfit dislocations remaining in the interface. Tiller [17] presented a somewhat related model for the climb of interface dislocations associated with interstitial creation in the oxidation of silicon. The purpose of this paper is to analyze the details of interface dynamics to develop a general mechanism which coordinates the demands of bulk diffusion via vacancies with the behavior of the interface structure to effect the phase transformation. The analysis treats specifically a diffusion-driven phase transformation between disordered binary solid solutions [7].

Howe et al. [18] have considered glide emission of misfit dislocations from steps (risers) and climb of misfit dislocations along the step face of precipitates. This has led to a continued discussion of step/misfit dislocation interactions relative to transformation mechanisms [19-22]. Notably, misfit dislocations on terrace faces are considered to be sessile in those discussions [18-22], although it has been noted that more general climb processes could be relevant for interfaces between solid solutions [22]. Here we consider the climb of dislocations both in the terrace and step planes of a boundary and out of these planes. Climb of misfit dislocations out of the interface plane has been observed for epitaxial metal layers [23] and in nanoscale layer structures [24]. It is likely to occur also for the interdiffusional growth of thicker layers, and is possible for the growth of precipitates as observed for an Al-Mo system by Chang and Loretto [25]: the emanation by climb of an intrinsic interface dislocation from a precipitate interface or the nucleation of a climb loop with a portion deposited on the interface are geometrically equivalent processes as discussed for the grain boundary analog, for example, by Hirth [26]. Finally, the climb of misfit dislocations to a new terrace as a macroscopic ledge advances, enhanced by the vacancy flux effects mentioned earlier, is a specific means to account for the fate of 
misfit dislocations in the proposed ledge mechanism for diffusional precipitate growth [18].

The interface dislocations are considered to have Burgers vectors near those of perfect lattice vectors so that the only constraint to climb is the osmotic force associated with point defects. This corresponds to many observed examples of misfit dislocations [9]. For the cases where misfit dislocations have smaller Burgers vectors, climb (or glide) emission is still possible, and sometimes observed [27], but there would be an added activational barrier associated with the emission stage that would provide an additional kinetic constraint and make the process less likely. When the misfit dislocations are not perfect lattice vectors, climb into the lattice requires deposition of a different GBD at the interface, an energetically unfavorable process. Of course, at temperatures above about 0.6 of the melting point, where diffusion becomes appreciable, the osmotic forces associated with vacancy fluxes become large [28], so interface constraints can be readily overcome unless the barriers are of the order of vacancy formation energies or larger. The nucleation of prismatic loops, formation of spiral dislocations, and operation of BardeenHerring sources near Kirkendall interfaces all reflect these large osmotic forces, which can approach values equivalent to those produced by stresses of $\mu / 10$ (where $\mu$ is the shear modulus) of the order of theoretical glide strengths for perfect crystals [28].

\section{ANALYSIS}

In the extension of the simple terrace-ledge-kink (TLK) model for solid-vapor interfaces to describe the microstructure of an $\alpha / \beta$ interphase interface near a coincidence orientation (Fig. 1), the intrinsic interfacial edge dislocations can be decomposed into two independent sets of edge dislocations: one set with the Burgers vector parallel to the interface accommodates misfit between the $\alpha$ and $\beta$ lattices; the other set with the Burgers vector normal to the interface accommodates the misorientation between the two lattices. This structure can also be applied to dislocations lying along multi-atom height steps or kinks, as shown in Fig. 1. Therefore, Fig. 1, which illustrates misfit dislocations (type A) and misorientation dislocations (type B), can be considered as a general representation of an $\alpha / \beta$ interface close to a near-coincidence or simple O-lattice orientation. For the precipitation case, one would imagine the ledges to be macroscopic in height, while for the layer growth case they could be of monatomic height. To avoid long-range elastic stresses associated with the interface, the height of the macroscopic ledges should be an integral number of misfit dislocation spacings.

Consider the advance to the right of the ledge in Fig. 1, corresponding to a transformation of $\alpha$ into $\beta$ with preservation of the terrace interface structure. For this case, some fraction of the vacancy flux difference at the $\alpha / \beta$ interface inherent to the interdiffusion process (described in the preceding paper) must be annihilated by the climb of the misfit dislocations (type A) both in the ledge and in the transformed terrace. This particular stage is mandatory, as it constitutes the phase transformation, and accommodates the volume change. On the other hand, to satisfy the remaining creation or annihilation of vacancies by the interface required by the diffusional vacancy flux difference, the climb of the misfit dislocations out of the terrace and/or the climb of the misorientation dislocations within the interfacial terraces would be required. As shown as Fig. 2, the phase transformation itself must involve the climb of

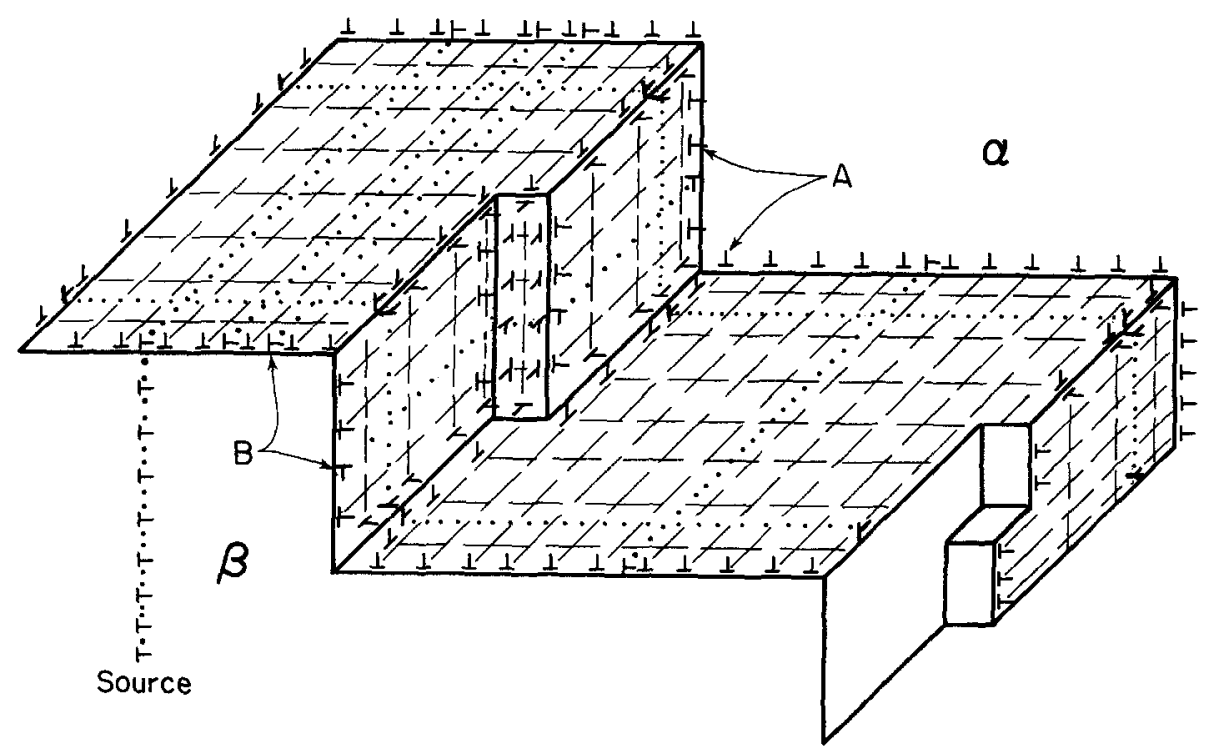

Fig. 1. Schematic illustration of terrace-ledge-kink model for $\alpha / \beta$ interface at a near-coincidence orientation. 


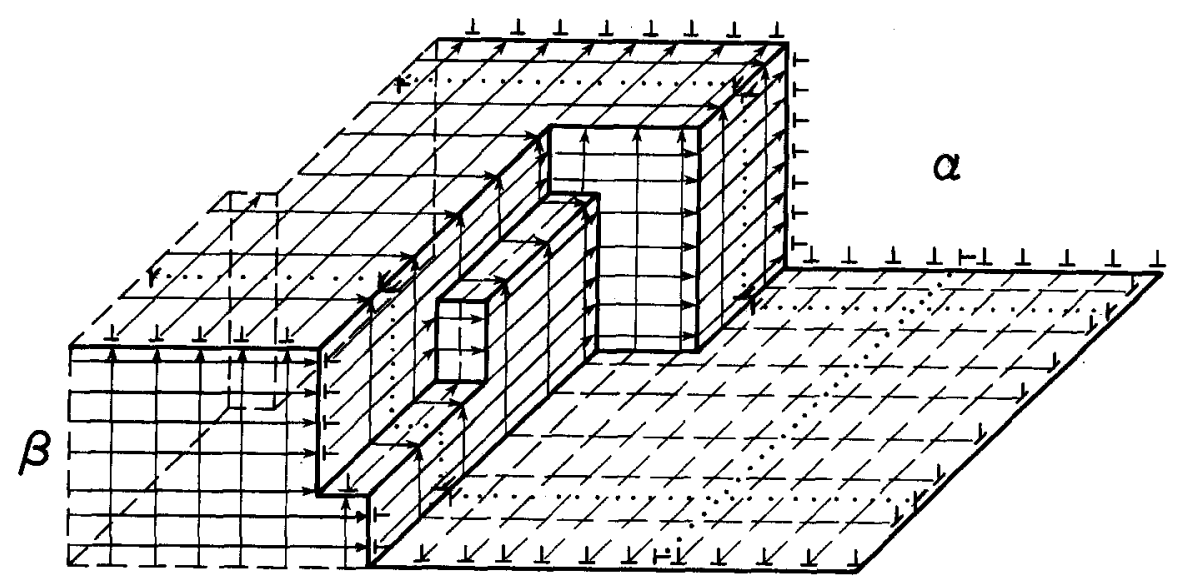

Fig. 2. Schematic illustration of transformation of $\beta$ to $\alpha$ phase resulting from sequential climb of misfit dislocations in an advancing ledge (step).

the misfit dislocations in the ledge and in its path, an action which is tied to the general activity of the interface in creating and annihilating vacancies. In Fig. 2, as the macroledge advances, the misfit dislocations must rise to the newly created terrace, e.g. by climbing up the macroledge or by other processes as discussed in Refs [18] to [22]. Clearly a cooperative interaction between the ledge migration (phase transformation) and the balance of vacancy fluxes must be maintained.

Figure 3 illustrates three elementary steps which supply $(\beta \rightarrow \alpha)$ or consume $(\alpha \rightarrow \beta)$ the vacancies associated with the climb of interfacial misfit dislocations constituting the transformation (Fig. 2): (a) the vacancy flux difference at the interface resulting from differing diffusion fluxes for $\mathbf{A}$ and $\mathbf{B}$ species in the bulk, $\Delta J_{\mathrm{VI}}^{\text {diff }}=J_{\mathrm{VI}}^{\beta}-J_{\mathrm{VI}}^{\alpha}=\dot{K}^{\alpha}+\dot{K}^{\beta}$ [as explained in the preceding paper (7)], (b) climb of misorientation (type B) dislocations in the interface terrace, and (c) climb of misfit (type A) dislocations out of the interface terrace. According to the definition of $\Delta J_{\mathrm{VI}}^{\mathrm{diff}}$, a positive magnitude represents vacancy creation at the interface, whether this net vacancy flux enters either the $\alpha$ or the $\beta$ phase. The positive climb for dislocations by steps (b) and (c) in Fig. 3 achieves vacancy annihilation. The vacancy creation or annihilation would occur at dislocation jogs or ledge kinks. Vacancy transport within the interfacial dislocation grid can proceed by bulk diffusion, by pipe diffusion along the dislocations or, if Suzuki segregation of vacancies to the interface were to occur, for example, by interface diffusion. The pipe or interface diffusion jump frequencies would be greater than those in the bulk. The pipe diffusion could involve local vacancy equilibration at jogs and/or kinks along the dislocation lines. The resulting local equilibrium of vacancies at ledges, related to the stress state through osmotic forces, would lead to a cooperative interaction between ledge migration and the vacancy flux balance.

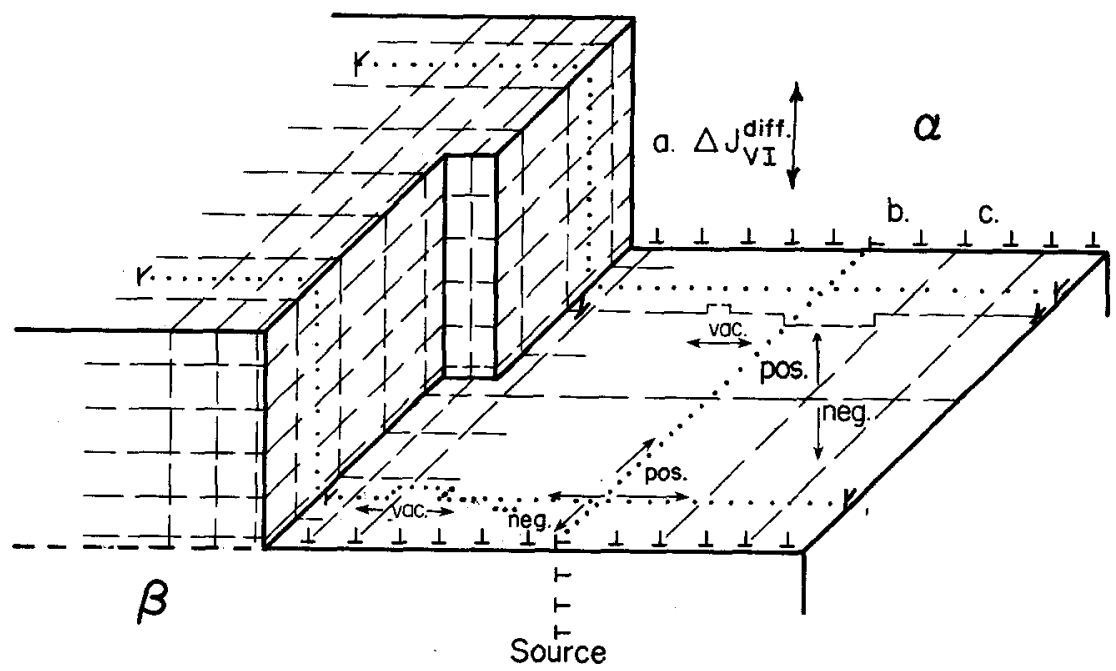

Fig. 3. Schematic illustration of vacancy supply/consumption and transport stages associated with phase transformation by ledge (step) advance. Positive and negative directions of climb are shown for the interface dislocations. 
Globally, the rates for the four steps at the interface during the transformation must satisfy the condition

$$
\Delta J_{\mathrm{Vl}}^{\text {diff }}+\dot{n}_{\mathrm{V}}(\|)+\dot{n}_{\mathrm{V}}(\perp)+\dot{n}_{\mathrm{V}}^{\text {trans }}=0
$$

where $\dot{n}_{\mathrm{V}}(\|)$ and $\dot{n}_{\mathrm{V}}(\perp)$ are the rates of vacancy creation (or annihilation) per unit area of interface by the positive (or negative) climb of misfit and misorientation edge dislocations of the terrace, respectively, and $\dot{n}_{\mathrm{v}}^{\text {trans }}$ is the rate of change in vacancy number produced by the climb of misfit dislocations required for the transformation. The quantity $\dot{n}_{\mathrm{v}}^{\text {trans }}$ arises because of the difference in molar volumes for the $\alpha$ and $\beta$ phases and/or the $\alpha / \beta$ mutual orientation relationship. For a given transformation, the relative contributions of these individual steps should depend greatly on the specific contacting planes, which decide the degree of misfit (and therefore the density and arrangement of the misfit dislocations), and on the misorientation of the planes from a near-coincidence orientation, which decides the density and arrangement of the misorientation dislocations. The renewal of the latter defects is dependent upon the presence of either glide sources in the bulk, as indicated in Fig. 3 , or of Bardeen-Herring type sources on the terraces.

As sketched in Fig. 4, and as previously suggested for vacancy annihilation in the $\mathrm{Ni} / \mathrm{NiO}$ system [16], the climb of some fraction of the misfit dislocations out of the terrace would lead to an increase in spacing of misfit dislocations in the terrace. In Fig. 4(a), misfit edge dislocations of spacing $s_{i}^{0}$ in the $i$ th direction are shown for an initial $\alpha / \beta$ interface where the reactive bulk compositions for the $\alpha$ and $\beta$ phases are brought into contact. In Fig. 4(b), the climb of some misfit dislocations into both the $\alpha$ and $\beta$ phases during an

(a)

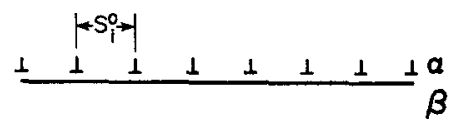

(b)

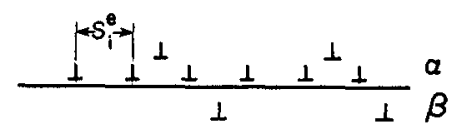

(c)

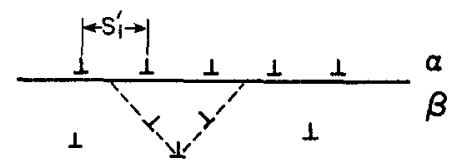

(d)

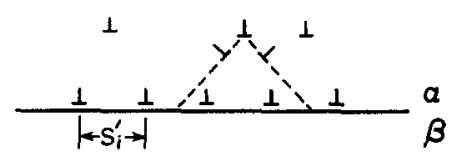

Fig. 4. Schematic two-dimensional illustration of combined climb and return glide of parallel terrace dislocations to effect vacancy annihilation/creation. (a) Initial $\alpha / \beta$ interface; (b) equilibrium $\alpha / \beta$ interface; (c) negative climb of misfit edge dislocations, vacancy creation; (d) positive climb of misfit edge dislocations, vacancy annihilation. (a)
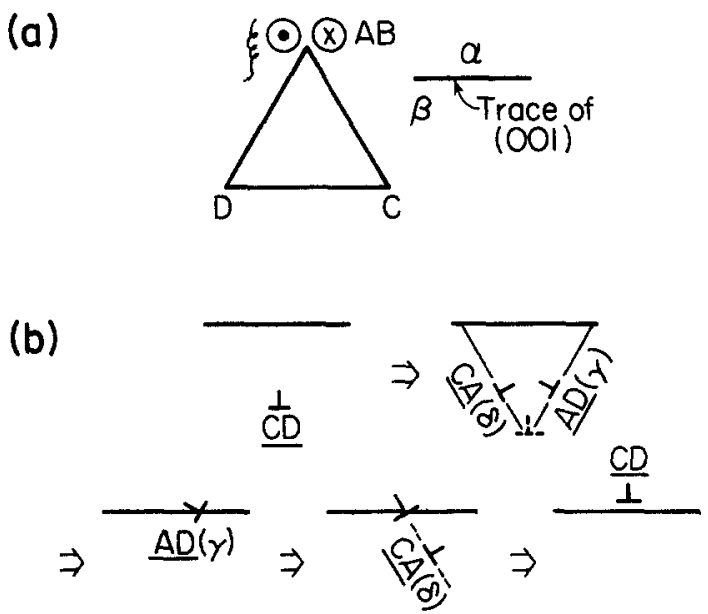

Fig. 5. (a) Thompson tetrahedron, sense vector, and orientation of $\alpha / \beta$ interface. (b) Glide reaction to move set of $\mathbf{C D}$ dislocations to interface.

initial transient period serves to accommodate the composition gradients and to adjust (increase) the spacing of the misfit dislocations to the equilibrium spacing $s_{i}^{\mathrm{e}}$. Such transient interdiffusion has been described by Hwang et al. [29] for thin film Au-Pd diffusion couples and by Nakahawa and Greenfield [30] for thin $\mathrm{Cu}-\mathrm{Ag}$ couples. The dislocations which climb from the interface into the bulk $\alpha$ and $\beta$ phases can be effective in creating and annihilating the vacancies required by the Kirkendall effect to compensate for the differences in the intrinsic diffusion coefficients in both the $\alpha$ and $\beta$ phases [7]. In Fig. 4(c), after transient interdiffusion has established the equilibrium $\alpha / \beta$ interfacial compositions (and $s_{i}^{e}$ ), the negative climb of some fraction of these misfit dislocations into the bulk of the $\beta$ phase would effect vacancy creation. The resulting increased spacing from $s_{i}^{e}$ to $s_{i}^{\prime}$ of the misfit dislocations would introduce local stresses into the $\alpha / \beta$ interface. Figure $4(d)$ illustrates the similar facility for positive climb of some misfit dislocations into the alpha phase corresponding to vacancy annihilation. As explained earlier [16], the climb steps described for two dimensions in Fig. 4 occur in three dimensions for an intersecting pair of dislocations from the terrace grid.

In Fig. 4, any elastic stress created by dislocation climb into the bulk produces a driving force to return, by glide, some of these dislocations from the bulk to the terrace if suitable dissociation reactions and glide planes exist for the specific interface considered. A specific example of the climb-glide ratchet process of Fig. 4(c) is presented for the case of two f.c.c. crystals in Fig. 5. The interface plane is assumed to be (001) with a square cross-grid of edge dislocations with Burger vectors $\mathbf{A B}$ and $\mathbf{C D}$, in the Thompson notation [31], accommodating $\alpha / \beta$ misfit. As shown for the set $\mathbf{C D}$, the dislocations can dissociate into $\mathbf{C A}(\delta)$ and $\mathbf{A D}(\gamma)$, glide back into the interface and recombine to form $\mathbf{C D}$ in the interface. The initial dissociation is energetically unfavorable and can only occur 
in the presence of an elastic driving force. The reaction is analogous to that for forming Lomer-type dislocations at or near the interfaces of strained layer structures.

As a specific proposal for this model, the climb of misfit dislocations from the terrace, illustrated in Fig. 4, should be able to furnish the bulk $\alpha$ and $\beta$ phases with the misfit dislocations required for two coincident processes: (i) to compensate for the continuous variation in lattice parameter associated with the concentration gradients $[23,27,29,30]$, and (ii) to effect the ereation/annihilation of vacancies in the bulk required to compensate for the differing intrinsic diffusion coefficients of A and B in both $\alpha$ and $\beta$ [7]. In the first case, as reactive diffusion couples develop concentration gradients in each phase, misfit dislocations should climb from the interface terrace into the bulk of each phase. In general, because the diffusivities in the two phases will differ $\left(\Delta J_{\mathrm{VI}} \neq 0\right)$, the relative amounts of dislocation climb/glide in the $\alpha$ and $\beta$ phase should differ. This effect would be more pronounced in the early stages of diffusion when concentration gradients are changing most rapidly with time. Thus, the dislocations may lag behind their elastic equilibrium positions.

At steady state, the required direction of dislocation climb to relax stresses associated with changing composition profiles and to satisfy interdiffusion requirements $\left(\Delta J_{\mathrm{VI}}^{\text {diff }}\right)$ may be in the same or in the opposite direction of climb motion that would accommodate vacancy annihilation/creation required to effect the phase transformation $\left(\dot{n}_{\mathrm{V}}^{\text {trans }}\right)$. In the case that these terms in equation (1) have opposite signs, the effect should not retard the rate of diffusionlimited transformation. If these two terms should have the same sign, some kinetic retardation could occur. There could be an added constraint to climb if misfit dislocations have to climb via vacancy annihilation into the phase in which the diffusion coefficients are smaller or where there is a requirement for vacancy creation at a remote position in the bulk. Analogously, an elastic constraint would arise from elastic incompatibility if the dislocations would climb into the phase with higher elastic modulus to produce the needed vacancy flux balance. In these instances, the constraints would tend to bias the vacancy balance in favor of climb by the misorientation dislocation set $B$ relative to the misfit set $A$ in Fig. 1.

\section{LEDGE DYNAMICS FOR PHASE TRANSFORMATION}

Figure 6 illustrates schematically a semicoherent $\alpha / \beta$ interface for two limiting cases: (i) in the foreground, kinks of dimensions $h_{\mathrm{K}}$ in the ledge (steps) of spacing $\lambda_{\mathrm{L}}$ and height $h_{1}$ are numerous in the macrostep of height $h_{\mathrm{L}}\left(\lambda_{\mathrm{K}}<h_{\mathrm{L}}\right)$, and the kinks serve as reversible sites for atomic attachment, while in (ii), in the background, kinks in the riser on the ledge are scarce $\left(\lambda_{\mathrm{K}}>h_{\mathrm{L}}\right)$. In the latter case, some kinetic difficulty in the attachment of atoms to the riser in the ledge could be introduced. The situation is analogous to that treated by Burton et al. [32] for crystal growth and resembles in part the extension of these ideas to solid state transformations by Aaronson et al. [33]. The natural site of the transformation is at the kinks in ledges with point source diffusion fields around them. These vacancy concentration gradients overlap along ledges, to produce line sources or sinks, and the overlap of ledge fields tends to produce planar sources or sinks for the terraces.

Interfacial diffusional constraints increasingly limit the transformation as the respective diffusional mean free paths (including bulk and interface contributions) become less than the respective spacings: for kinks, when $\bar{x}_{\mathrm{K}}<h_{\mathrm{L}}$ or $\lambda_{\mathrm{K}}$; for microledges on the large macroledges when $\bar{x}_{1}<\lambda_{1}$; and for terraces when $\bar{x}_{\mathrm{T}}<\lambda_{\mathrm{T}}$. The kinetics for the transformation can then be analyzed. The linear rate of advance of the ledge in the $y$ direction, $v_{\mathrm{L}}$, is given in terms of the step velocity $v_{1}$ by

$$
v_{\mathrm{L}}=v_{1} h_{1} / \lambda_{1}
$$

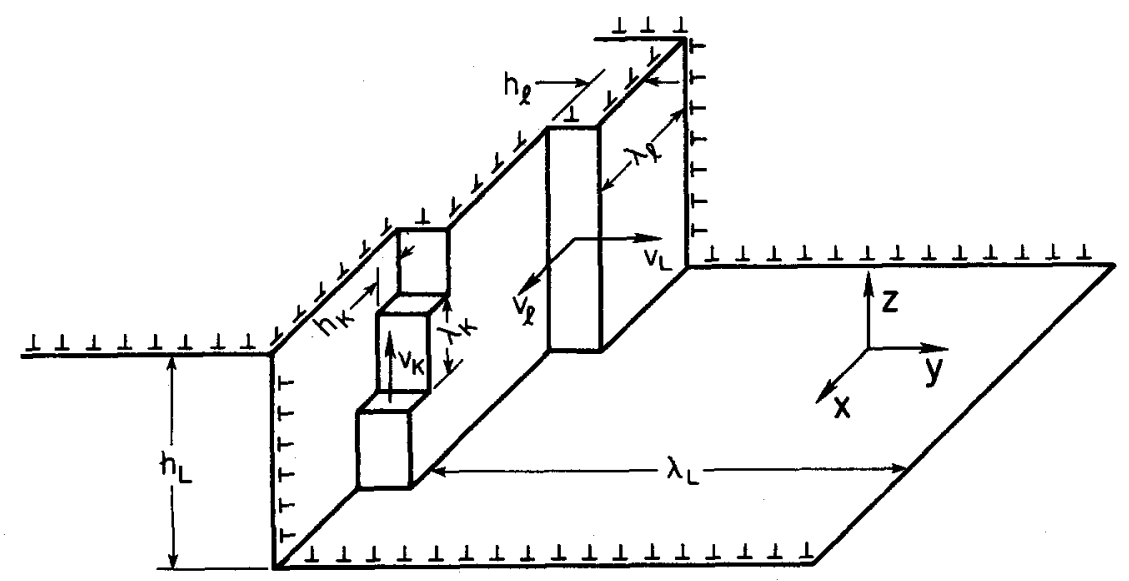

Fig. 6. Schematic illustration of semicoherent $\alpha / \beta$ interface. 
leading to a rate of volume transformed per unit area of interface equal to

$$
\dot{V}=v_{1} h_{1} h_{\mathrm{L}} / \lambda_{1} \lambda_{\mathrm{L}} .
$$

This rate of volume transformation is related to $\dot{N}$, the growth rate relative to the Matano plane [7], in the centered mole-number frame of reference, by the expression

$$
\dot{V}=\dot{N} V_{\mathrm{m}}
$$

where $V_{\mathrm{m}}$ is the molar volume for the growing $\beta$ phase.

Let us consider the case, Fig. 2, where the vacancy flux accommodation occurs by the climb of misfit dislocations. A semicoherent ledge with a rectangular grid of misfit dislocations is chosen so that its height $h_{\mathrm{L}}$ is an integral number times the spacing $s$ of the misfit edge dislocations. For the equilibrium situation

$$
s_{i}^{\mathrm{e}}=\bar{a}_{i}^{2} / \Delta a_{i}
$$

where $\bar{a}_{i}$ is the average lattice parameter, and $\Delta a_{i}$ is the difference in lattice parameters for the equilibrium $\alpha$ and $\beta$ compositions in the $i$ th direction of an epitaxial orientation. As discussed for the case illustrated in Fig. 4, during the diffusion-driven phase transformation, the climb of a fraction of the misfit dislocations from the interface into the bulk phases changes the average interfacial dislocation spacing from $s_{i}^{0}$ to $s_{i}^{\mathrm{e}}$, or to $s_{i}^{\prime}$ with an associated increase in strain energy.

According to Fig. 2, the transformation from $\alpha$ to $\beta$ requires the positive climb of the misfit dislocations in the advancing ledge and in its traversed path. In particular, three different sets of parallel misfit dislocations in the $x-y, y-z$ and $x-z$ planes need to be translated by climb along the $z, x$, and $y$ axes, respectively, to effect the transformation. For the climb of each set of the misfit dislocations in one plane, the number of vacancies consumed per unit length of misfit dislocation per unit climb distance is given by

$$
n_{\mathrm{v}}^{\prime}=b / \mathbf{\Omega}
$$

where $b$ is the edge component of the Burgers vector and $\Omega$ is the atomic volume for the growing $\beta$ phase. The length of misfit dislocation lines per unit area of interface is given by $s^{-1}$ so that the required vacancy flux for the translation of this set of parallel misfit dislocations is given by

$$
\dot{n}_{\mathrm{v}}=\dot{V}_{\mathrm{b}} / \mathbf{\Omega}=\boldsymbol{v}_{\mathrm{c}} / s
$$

where $v_{\mathrm{c}}$ is the dislocation climb velocity and $s$ is the average spacing of the misfit dislocations. Alternatively, for a volume $V$ transformed per unit interfacial area, the necessary climb volume to move the misfit dislocations is $b \mathrm{~V} / \mathrm{s}$, corresponding to a number of vacancies per unit area $n_{\mathrm{v}}=b V / s \Omega$. The time rate of change of this expression again gives equation (7).

Similar expressions apply for the climb of the other two sets of misfit dislocations, so that for the rate of volume transformation per unit interface area expressed by equation (3), the required rate of change in vacancy number that would be used in equation (1) is given by

$$
\dot{n}_{\mathrm{V}}^{\text {trans }}=\dot{V} \frac{b}{\Omega}\left(1 / s_{x}+1 / s_{y}+1 / s_{z}\right) .
$$

One may consider that this contribution to the creation/annihilation of vacancies is achieved by the climb of misfit dislocations within the interface.

Finally, to effect the balance of sites described by equation (1), the climb rate per unit length for interfacial dislocations $\left[\dot{n}_{\mathrm{V}}(\|)+\dot{n}_{\mathrm{v}}(\perp)\right]$ needs to be determined as a diffusional boundary value problem, in general a difficult procedure. As a simple example, in the limiting case that the vacancy source-sink distance $R$ exceeds the misfit dislocation spacing $s$, the climb rate is given by [34]

$$
\dot{n}_{\mathrm{v}}=\frac{2 \pi D_{\mathrm{s}}}{s b \ln (R / b)}\left[\ln \left(\frac{C_{\mathrm{v}}}{C_{\mathrm{v}}^{0}}\right)-\frac{\sigma \Omega}{k T}\right]
$$

where $D_{\mathrm{s}}$ is the appropriate self-diffusivity, $C_{\mathrm{v}}$ is the local vacancy concentration at the interface, $C_{\mathrm{V}}^{0}$ is the remote vacancy equilibrium concentration, and $\sigma$ is the elastic back-stress. When $s<R$, diffusional overlaps occur and the kinetic expressions become more complicated, analogous to the crystal growth case [32].

\section{SUMMARY}

In a diffusional phase transformation, the divergence of intrinsic diffusion fluxes at the interface that accompanies the growth of a phase leads as well to a divergence of vacancy fluxes at the interface. This divergence leads to the necessity for local climb processes involving misfit or misorientation dislocations at the interface. The requisite response of the terrace dislocations to the motion of ledges in the interface couples the interfacial defects associated with semi-coherency to the phase transformation. Vacancy transport (communication) between the ledges and the terraces could occur by exchange at jogs/kinks or pipe diffusion in the cores of the terrace dislocations. The climb-related processes may either retard or enhance the degree of interface control of the phase transformation depending on the sign of the vacancy flux divergence.

The ideas developed here are presented for a general case of a diffusional phase transformation involving disordered solid solutions. The model may be directly applied to scaling reactions, displacement reactions involving layered products, layer structures formed by interdiffusion, and precipitation reactions. The model can be extended to apply as well to bainitic-type reactions, but a more detailed consideration of the coupling with transformation dislocations and ledges at the growth interface would be required for a specific case. 
Acknowledgement - The financial assistance of NATO for the Collaborative Research Grant $0777 / 87$ is gratefully knowledged.

\section{REFERENCES}

1. W. Jost, Diffusion in Solids, Liquids and Gases. Academic Press, New York (1952).

2. P. G. Shewmon, Diffusion in Solids. McGraw-Hill, New York (1963)

3. J. Philibert, Diffusion et Transport de Matiere dans les Solides. Les Editions de Physique, Les Ulis (1986).

4. J. W. Matthews, Phil. Mag. 8, 711 (1963).

5. J. W. Matthews, Thin Solid Films 25, 199 (1975).

6. A. M. Beers and E. J. Mittemeijer, Thin Solid Films 48 , 367 (1978).

7. F. J. J. van Loo, B. Pieraggi and R. A. Rapp, Acto metall. mater. 38, 1769 (1990).

8. W. Bollmann, Crystal Defects and Crystalline Interfaces. Springer, Berlin (1970).

9. J. W. Matthews, in Dislocations in Solids (edited by F. R. N. Nabarro), Vol. 2, p. 461. North Holland Amsterdam (1979).

10. R. W. Balluffi and G. B. Olson, Metall. Trans. 16A, 529 (1985).

11. G. Garmong and C. G. Rhodes, Acta metall. 22, 1373 (1974).

12. R. C. Pond, in Dislocations and Properties of Real Materials, p. 71. Inst. of Metals, London (1985)

13. J. P. Hirth and R. W. Balluffi, Acta Metall. 21, 929 (1973).

14. T. Takasugi, N. Fat. Halla and O. Izumi, Acta metall 2, 111 (1979).

15. H. I. Aaronson, T. Furuhara, J. M. Rigsbee, W. T Reynolds $\mathrm{Jr}$ and $\mathrm{J}$. M. Howe, Metall. Trans. A. In press.

16. B. Pieraggi and R. A. Rapp, Acta metall. 36, 1281 (1988).
17. W. A. Tiller, J. Electrochem. Soc. 127, 625 (1980).

18. J. M. Howe, T. Abinandanan, C. S. Chiang, T. Furuhara, N. Prabhu and H. I. Aaronson, Scripto metall. 21, 1639 (1987).

19. H. I. Aaronson and W. T. Reynolds, Scripta metall. 22, 567,575 (1988).

20. J. W. Christian and D. V. Edmonds, Scripta metall. 22, 573, 577 (1988).

21. H. I. Aaronson, J. M. Rigsbee, T. Foruhara, N. Prabhu, W. T. Reynolds Jr and J. M. Howe, Scripta metall. 23, 279 (1989).

22. J. W. Christian and D. V. Edmonds, Scripta metall. 23, 285 (1989).

23. K. Shinohara and J. P. Hirth, Phil. Mag. 27, 883 (1973); Thin Solid Films 16, 345 (1973).

24. Z. J. Radzimski, B. L. Jiang, G. A. Rozgonyi, T. P Humphreys, N. Hamaguchi, and S. M. Bedair, J. appl. Phys. 64, 2328 (1988).

25. C. P. Chang and M. H. Loretto, Acta metall. 36, 805 (1988).

26. J. P. Hirth, Metall. Trans. 3, 3047 (1972).

27. Z. Shen, R. H. Wagoner and W. A. T. Clark, Acta metall. 36, 3231 (1988).

28. J. P. Hirth and J. Lothe, Theory of Dislocations, 2nd edn, p. 613. Wiley, New York (1982).

29. M. Hwang, D. E. Laughlin and I. M. Bernstein, Acta metall. 33, 1195 (1985).

30. Y. G. Nakagawa and I. G. Greenfield, Acta metall. 21, 367 (1973).

31. J. P. Hirth and J. Lothe, Theory of Dislocations, 2nd edn, p. 319. Wiley, New York (1982)

32. W. K. Burton, N. Cabrera and F. L. Frank, Phil. Trans. R. Soc. 243, 299 (1951).

33. H. I. Aaronson, C. Laird and K. R. Kinsman, in Phase Transformations, p. 313. Am. Soc. Metals, Metals Park, Ohio (1970).

34. J. P. Hirth and J. Lothe, Theory of Dislocations, 2nd edn, p. 562. Wiley, New York (1982). 